Article

\title{
Optimization of Baker's Yeast Production on Date Extract Using Response Surface Methodology (RSM)
}

\author{
Mounira Kara Ali ${ }^{1, *}$, Nawel Outili ${ }^{2}$, Asma Ait Kaki ${ }^{3}$, Radia Cherfia ${ }^{1}$, Sara Benhassine ${ }^{1}$, \\ Akila Benaissa $^{2}$ and Noreddine Kacem Chaouche ${ }^{1}$
}

1 Laboratoire de Mycologie, de Biotechnologie et de l'Activité Microbienne (LaMyBAM), Département de Biologie Appliquée, Faculté des Sciences de la Nature et de la Vie, Université Frères Mentouri Constantine 1, Constantine 25000, Algeria; cherfiarr@yahoo.fr (R.C.); sarabenhassine@gmail.com (S.B.);

nkacemchaouche@yahoo.fr (N.K.C.)

2 Laboratoire de Génie des Procédés de l'Environnement, Faculté du Génie des Procédés, Université Constantine 3, Constantine 25000, Algeria; out.nawel@gmail.com (N.O.); akilabenaissa@yahoo.fr (A.B.)

3 Département de Biologie, Faculté des Sciences de la Nature et de la Vie, Université M'hamed Bougera, Boumerdess 35000, Algeria; askaki.biotechno@gmail.com

* Correspondence: kr.mounira@yahoo.fr; Tel.: +213-55-57-73-223

Received: 16 July 2017; Accepted: 3 August 2017; Published: 7 August 2017

\begin{abstract}
This work aims to study the production of the biomass of S. cerevisiae on an optimized medium using date extract as the only carbon source in order to obtain a good yield of the biomass. The biomass production was carried out according to the central composite experimental design (CCD) as a response surface methodology using Minitab 16 software. Indeed, under optimal biomass production conditions, temperature $\left(32.9^{\circ} \mathrm{C}\right), \mathrm{pH}(5.35)$ and the total reducing sugar extracted from dates $(70.93 \mathrm{~g} / \mathrm{L})$, S. cerevisiae produced $40 \mathrm{~g} / \mathrm{L}$ of their biomass in an Erlenmeyer after only $16 \mathrm{~h}$ of fermentation. The kinetic performance of the $S$. cerevisiae strain was investigated with three unstructured models i.e., Monod, Verhulst, and Tessier. The conformity of the experimental data fitted showed a good consistency with Monod and Tessier models with $R^{2}=0.945$ and 0.979 , respectively. An excellent adequacy was noted in the case of the Verhulst model $\left(R^{2}=0.981\right)$. The values of kinetic parameters $\left(K s, X_{m}, \mu_{m}, p\right.$ and $\left.q\right)$ calculated by the Excel software, confirmed that Monod and Verhulst were suitable models, in contrast, the Tessier model was inappropriately fitted with the experimental data due to the illogical value of Ks (-9.434). The profiles prediction of the biomass production with the Verhulst model, and that of the substrate consumption using Leudeking Piret model over time, demonstrated a good agreement between the simulation models and the experimental data.
\end{abstract}

Keywords: Saccharomyces cerevisiae; biomass; date extract; optimization; response surface methodology; kinetic models

\section{Introduction}

For thousands of years, micro-organisms have been spontaneously used in human food preparation. However, scientists did not initiate studying these living beings until the appearance of the microscope in 1680. Among microorganisms widely studied and used in diverse biotechnological applications, the yeast $S$. cerevisiae was mentioned [1-3]. This yeast species was known formerly for its particular exploitation in the production of wine, beer and bread. Recently, it has been used as a "cell factory", able to synthesize a large spectrum of bioactive molecules as recombinant proteins, antibiotics and bioethanol [4-7]. Algeria records a remarkable lack in beet and cane molasses production, indeed, it imports about 18,000 and 13,000 tons per year of each one, respectively, and also imports the yeast strain S. cervisiae used as a baker's leaven [8]. However, Algeria has an enormous potential of dates $[9,10]$. In addition, the production of $S$. cerevisiae biomass from a low quality date variety could 
constitute an economic carbon source, especially considering that the production of dates is a bountiful in Algeria. The main objective of the present work is to study the optimization of S. cerevisiae biomass production, using date extract as a sole carbon source.

The traditional technique used for optimizing a multivariable fermentation process is difficult and does not take the alternative effects between components into consideration [11,12]. Recently, many statistical experimental design methods have been employed in bioprocess optimization [13-16]. Among these, the central composite experimental design (CCD) is the most suitable for identifying the individual variables to optimize a multivariable system $[17,18]$. This method was used to optimize many fermentation process, such as acids, antibiotics, enzymes, biomass and ethanol production by several micro-organisms types [19-22]. Furthermore, it was used in design, analysis, and in unit operations. The advantages of this method are the reduction of the number of experiments, reagents, time, financial input and energy [23]. The present work was conducted following these steps: (a) selecting the optimum conditions of three parameters (temperature; initial $\mathrm{pH}$, and sugar concentration extracted from dates) to obtain a high yield of $S$. cerevisiae cells growth using a surface response methodology; (b) exploit the date extract as the sole carbon source for the production of S. cerevisiae at optimized conditions; (c) predict the biomass production process by unstructured kinetic models.

\section{Materials and Methods}

\subsection{Origin and Reactivation of the Yeast S. cerevisiae}

The yeast used in this study has a commercial origin in fact, it is produced by the factory Lesaffre. The lyophilized form of $S$. cerevisiae was chosen due to several advantages, such as its availability, rapid growth, resistance to contaminants, easy cultivation, ability to consume most sugar and high yield production. The yeast was reactivated on agar plates containing YPGA medium composed of yeast extract $10 \mathrm{~g} / \mathrm{L}$, peptone $10 \mathrm{~g} / \mathrm{L}$, glucose $20 \mathrm{~g} / \mathrm{L}$, agar $20 \mathrm{~g} / \mathrm{L}$ with a pH 6, incubated at $30^{\circ} \mathrm{C}$ for $24 \mathrm{~h}$. After development, the yeast was analyzed by macroscopic and microscopic characteristics in order to confirm its aspect.

\subsection{Preparation of Dates Extract}

The date variety used in this study is very widespread in the south-eastern region of Algeria. It is the dry variety Mech-Degla. This variety has a sub-cylindrical shape, slightly narrowed at its tip. It is lightly beige-tinted. The epicarp is wrinkled, shiny and brittle. The mesocarp is not very fleshy of a dry consistency and fibrous texture (Figure 1) [8]. The choice of this variety is justified by its abundance at the national level, low market value, ease of preservation (dry date) and richness in sugars. This variety is therefore a favorable substrate for the yeast growth and development.

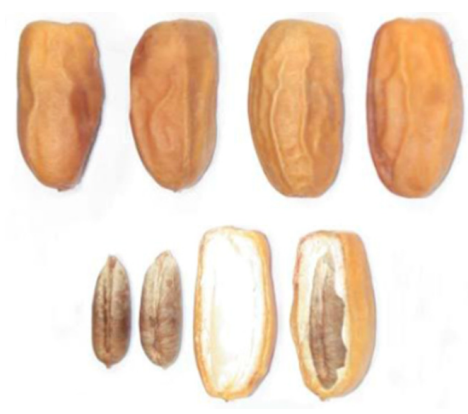

Figure 1. Dates Mech-Degla.

To prepare the date extract, $1 \mathrm{~kg}$ of this date is washed, peeled and placed in $5 \mathrm{~L}$ of distilled water and then boiled at $100{ }^{\circ} \mathrm{C}$ for one hour in order to extract the sugars. The obtained extract is filtered 
through muslin to remove the large particles, and then the solution is centrifuged at $5000 \mathrm{rpm}$ for 5 min. The supernatant obtained constitutes the date extract [24].

\subsection{Preparation of Culture Medium Based on the Dates Extract and Inoculums}

The method cited by Kocher and Uppal [25] was used with minor modifications. The obtained date extract from the above preparation was supplemented by mineral salts: magnesium sulfate $0.44 \mathrm{~g}$, urea $12.70 \mathrm{~g}$, and ammonium sulfate $5.30 \mathrm{~g}$. Finally, the medium was distributed in an Erlenmeyer of $250 \mathrm{~mL}$ with a ratio of $100 \mathrm{~mL}$ per flask and sterilized at $120^{\circ} \mathrm{C}$ for $20 \mathrm{~min}$. The pre-culture was obtained by inoculating two colonies of the yeast $S$. cerevisiae in $250 \mathrm{~mL}$ shake flasks containing $100 \mathrm{~mL}$ of dates extract, mentioned above. The pre-culture was incubated at $30^{\circ} \mathrm{C}$ for $3 \mathrm{~h}$, and used further as inoculums for the yeast biomass production.

\subsection{Statistical Design of Experiments}

\subsubsection{Factor Selection and Organization of Experiments}

The organization of the experiments was carried out using the experimental design obtained by the central composite experimental design (CCD). Three independent variables were selected (temperature, initial $\mathrm{pH}$ and concentration of sugars extracted from dates). Table 1 shows the domain of study with coded levels and real values of studied variables.

Table 1. Coded levels and real values of studied variables.

\begin{tabular}{cccccc}
\hline \multirow{2}{*}{ Variables } & \multicolumn{5}{c}{ Coded Levels } \\
\cline { 2 - 6 } & $-\alpha$ & -1 & 0 & +1 & $+\alpha$ \\
\cline { 2 - 6 } & \multicolumn{5}{c}{ Real Values } \\
\hline$X_{1}=$ Temperature $\left({ }^{\circ} \mathrm{C}\right)$ & 27 & 29 & 33 & 37 & 39 \\
$X_{2}=$ Initial $\mathrm{pH}$ & 2.4 & 3.6 & 5.5 & 7.3 & 8.6 \\
$X_{3}=$ concentration of sugars $(\mathrm{g} / \mathrm{L})$ & 1 & 44.1 & 107.5 & 170.9 & 214 \\
\hline
\end{tabular}

In the central composite design, the -1 and +1 correspond to the lower and the higher level, respectively. The value 0 represents the central value of the rangeand $\alpha$ has the value of $1.68\left(\alpha=\sqrt[4]{ } N_{f}\right.$, where $N_{f}$ is a number of experiments).

The CCD matrix employed for three independent variables is given in Table 2. Each column represents the different variables (factors) and each line represents the different experiments (20).

Table 2. The central composite experimental design (CCD) matrix for different variables (coded levels).

\begin{tabular}{cccc}
\hline \multirow{2}{*}{ Experiments } & \multicolumn{3}{c}{ Coded Levels } \\
\cline { 2 - 4 } & $\mathbf{X}_{\mathbf{1}}$ & $\mathbf{X}_{\mathbf{2}}$ & $\mathbf{X}_{\mathbf{3}}$ \\
\hline 01 & -1 & -1 & -1 \\
02 & +1 & -1 & -1 \\
03 & -1 & +1 & -1 \\
04 & +1 & +1 & -1 \\
05 & -1 & -1 & +1 \\
06 & +1 & -1 & +1 \\
07 & -1 & +1 & +1 \\
08 & +1 & +1 & +1 \\
09 & -1.68 & 0 & 0 \\
10 & +1.68 & 0 & 0 \\
11 & 0 & -1.68 & 0 \\
12 & 0 & +1.68 & 0 \\
13 & 0 & 0 & -1.68 \\
14 & 0 & 0 & +1.68 \\
\hline
\end{tabular}


Table 2. Cont.

\begin{tabular}{cccc}
\hline \multirow{2}{*}{ Experiments } & \multicolumn{3}{c}{ Coded Levels } \\
\cline { 2 - 4 } & $\mathbf{X}_{\mathbf{1}}$ & $\mathbf{X}_{\mathbf{2}}$ & $\mathbf{X}_{\mathbf{3}}$ \\
\hline 15 & 0 & 0 & 0 \\
16 & 0 & 0 & 0 \\
17 & 0 & 0 & 0 \\
18 & 0 & 0 & 0 \\
19 & 0 & 0 & 0 \\
20 & 0 & 0 & 0 \\
\hline
\end{tabular}

The CCD matrix is composed of a complete factorial design, $2^{3}$; two axial points on the axis of each design variable at a distance of $\alpha=1.682$ from the design center and 5 points at the domain center. The actual experimental values corresponding to the coded levels used for the creation of the experiment matrix are presented below (Table 3).

Table 3. Actual values for the three independent variables.

\begin{tabular}{cccc}
\hline \multirow{2}{*}{ Experiments } & \multicolumn{3}{c}{ Actual Values } \\
\cline { 2 - 4 } & Temperature $\left({ }^{\circ} \mathbf{C}\right)$ & Initial $\mathbf{~ p H}$ & Sugars Concentration $(\mathbf{g} / \mathbf{L})$ \\
\hline 01 & 29 & 3.6 & 44.1 \\
02 & 37 & 3.6 & 44.1 \\
03 & 29 & 7.3 & 44.1 \\
04 & 37 & 7.3 & 44.1 \\
05 & 29 & 3.6 & 170.9 \\
06 & 37 & 3.6 & 170.9 \\
07 & 29 & 7.3 & 170.9 \\
08 & 37 & 7.3 & 170.9 \\
09 & 27 & 5.5 & 107.5 \\
10 & 39 & 5.5 & 107.5 \\
11 & 33 & 2.4 & 107.5 \\
12 & 33 & 8.6 & 107.5 \\
13 & 33 & 5.5 & 1 \\
14 & 33 & 5.5 & 214 \\
15 & 33 & 5.5 & 107.5 \\
16 & 33 & 5.5 & 107.5 \\
17 & 33 & 5.5 & 107.5 \\
18 & 33 & 5.5 & 107.5 \\
19 & 33 & 5.5 & 107.5 \\
20 & 33 & 5.5 & 107.5 \\
\hline
\end{tabular}

\subsubsection{Effect Estimation}

The real values $X$ have been calculated according to Equation (1).

$$
X=\frac{x-x_{0}}{\Delta x}
$$

Where $X$, is the coded value for the independent variable, $x$, is the natural value, $x_{0}$, is the natural value at the center point and $\Delta x$, is the step change value (the half of the interval $(-1+1)$ ). The mathematical model describing the relation between dependent and independent variables for this process has the quadratic form for the experimental design used:

$$
Y_{i}=\beta_{0}+\beta_{1} X_{1}+\beta_{2} X_{2}+\beta_{3} X_{3}+\beta_{11} X_{1}^{2}+\beta_{22} X_{2}^{2}+\beta_{33} X_{3}^{2}+\beta_{12} X_{1} X_{2}+\beta_{13} X_{1} X_{3}+\beta_{23} X_{2} X_{3}
$$

where $Y_{\mathrm{i}}$, is the predicted response (in our case, the Biomass production $(\mathrm{g} / \mathrm{L}) ; \beta_{0}$, is offset term; $\beta_{1}$, $\beta_{2}, \beta_{3}$ are the linear effects (showing the predicted response); $\beta_{11}, \beta_{22}, \beta_{33}$ are the squared effects $\beta_{12}$, $\beta_{13}, \beta_{23}$ are the interaction terms and $X_{1}, X_{2}, X_{3}$ are the independent variables. The calculation of the effect of each variable and the establishment of a correlation between the response $Y_{i}$ and the variables $X$, were performed using a Minitab 16 software (Minitab, Inc., State College, PA, USA). 


\subsubsection{Statistical Analysis}

The statistical analysis was performed using analysis of variance (ANOVA), in order to validate the square model regression. It included the following parameters: coefficient of determination $R^{2}$ Student test $(t)$; Fisher test $(F)$; and $p$-value. In our study, the statistical significance test level was set at $5 \%$ (probability $(p)<0.05)$.

\subsection{Validation of Biomass Production in Optimum Medium}

In order to confirm the optimized conditions obtained by the central composite design, an experiment was carried out on $250 \mathrm{~mL}$ shake flasks. To do this, $100 \mathrm{~mL}$ of date extract (mentioned above) was seeded with $11 \mathrm{~mL}$ of the yeast pre-culture and the $\mathrm{pH}$ of the medium was adjusted to 5.35 (optimum value). Shake flasks were sterilized at $120^{\circ} \mathrm{C}$ for $20 \mathrm{~min}$, and incubated at $32.9^{\circ} \mathrm{C}$ (optimum value) for $18 \mathrm{~h}$.

\subsection{Analytical Techniques}

\subsubsection{Determination of Total Reducing Sugars}

The total reducing sugars were determined according to the method of Dubois et al. [26], with minor modifications. The sample was filtered, and $1 \mathrm{~mL}$ of it was transferred to a glass tube. Then $0.6 \mathrm{~mL}$ of $5 \%(w / v)$ phenol and $3.6 \mathrm{~mL}$ of $98 \%$ sulfuric acid were added. The mixture was shaken and incubated at room temperature for $30 \mathrm{~min}$; sugar gives a cream yellow whose intensity is proportional to the amount of total sugars. The absorbance was measured at $490 \mathrm{~nm}$. A calibration curve was established using glucose as the standard.

\subsubsection{Determination of Biomass Concentration}

The measurement of biomass was followed by estimation of cell dry weight, expressed in $\mathrm{g} / \mathrm{L}$. one $\mathrm{mL}$ of yeast culture was centrifuged at $5000 \mathrm{rpm}$ for $5 \mathrm{~min}$. The supernatant obtained was washed twice with water and dried by incubation at $105^{\circ} \mathrm{C}$ until at a constant weight [27].

\subsection{Modeling}

Unstructured kinetic models using Monod, Verhulst, and Tessier [28] (Table 4) have been implemented to fit the experimental data. Kinetic parameters $\left(\mu_{\max }, K s\right.$ and $\left.X_{m}\right)$, were determined using the curve fitting method of each model. The fitness evaluation of experimental data on cell growth by models was performed using Excel software (Microsoft, Redmond, WA, USA).

Profile Prediction of Biomass and Substrate Concentration

To predict the experimental profile of biomass of $S$. cerevisiae during time fermentation, the integration of the Verhulst model was used to give a sigmoidal variation of $X$ as a function of $t$, which may represent both an exponential and a stationary phase (Equation (3)):

$$
X=\frac{X_{0} \mathrm{e}^{\mu_{m} t}}{\left\{1-\left(X_{0} / X_{m}\right)\left(1-\mathrm{e}^{\mu_{m} t}\right)\right\}}
$$

In addition, the substrate model (Leudeking Piret) as described below (Equation (4)) was also applied to predict an experimental profile for total reducing sugars consumption by S. cerevisiae during time.

$$
-\frac{\mathrm{d} S}{\mathrm{~d} t}=p \frac{d X}{d t}+q X
$$

where $p=1 / Y_{X / S}$ and $q$ is a maintenance coefficient. 
Table 4. Unstructured kinetic models to determinate the kinetic parameters.

\begin{tabular}{|c|c|c|c|c|}
\hline $\begin{array}{l}\text { Kinetic } \\
\text { Models }\end{array}$ & Equations & Linearized Form & Description & Symbols \\
\hline Monod & $\mu=\mu_{\max } \frac{S}{S+K_{S}}$ & $\frac{1}{\mu}=\frac{K_{S}}{\mu_{\max }} \frac{1}{S}+\frac{1}{\mu_{\max }}$ & $\begin{array}{l}\text { Monod kinetic model is a substrate } \\
\text { concentration dependent. }\end{array}$ & \multirow{3}{*}{$\begin{array}{l}\mu: \text { is the specific growth rate }\left(\mathrm{h}^{-1}\right) . \\
\mu_{\max }: \text { is the maximum specific growth rate }\left(\mathrm{h}^{-1}\right) \text {. } \\
K_{S}: \text { is the half-saturation constant }(\mathrm{g} / \mathrm{L}) . \\
S: \text { is the concentration in limiting substrate }(\mathrm{g} / \mathrm{L}) \text {. } \\
X: \text { is the biomass concentration }(\mathrm{g} / \mathrm{L}) . \\
X_{m}: \text { is the Maximum biomass concentration }(\mathrm{g} / \mathrm{L}) \text {. }\end{array}$} \\
\hline Verhulst & $\mu=\mu_{\max }\left(1-\frac{X}{X_{m}}\right)$ & $\mu=\mu_{\max }-\frac{\mu_{\max }}{X_{m}} X$ & $\begin{array}{l}\text { Verhulst kinetic model is an unstructured model depends } \\
\text { on biomass concentration. }\end{array}$ & \\
\hline Tessier & $\mu=\mu_{\max }\left(1-\mathrm{e}^{-K s S}\right)$ & $\ln \mu=\frac{1}{K_{s}} S+\ln \mu_{\max }$ & $\begin{array}{l}\text { Tessier is an unstructured model for a substrate } \\
\text { concentration dependent. }\end{array}$ & \\
\hline
\end{tabular}


Equation (4) is rearranged as follows:

$$
-d S=p d X+q \int X(t) d t
$$

Substituting Equation (3) in Equation (5) and integrating with initial conditions $\left(S=S_{0} ; t=0\right)$ give the following Equation:

$$
S=S_{0}-p X_{0}\left\{\frac{e^{\mu_{m} t}}{\left\{1-\left(\frac{X_{0}}{X_{m}}\right)\left(1-e^{\mu_{m} t}\right)\right\}}-1\right\}-q \frac{X_{m}}{\mu_{m}} \ln \left\{1-\frac{X_{0}}{X_{m}}\left(1-e^{\mu_{m} t}\right)\right\}
$$

\section{Results and Discussion}

Microbial growth is influenced by the culture medium constituents and the physico-chemical factors in particular, temperature, $\mathrm{pH}$, and substrate concentration. Indeed, in the present study, the temperature, the initial $\mathrm{pH}$ and the concentration of the carbon source (total sugars extracted from dates) were supposed to optimize the biomass production of $S$. cerevisiae using the central composite experimental design. The biomass concentration over $16 \mathrm{~h}$ of fermentation varied with the change in temperature, initial $\mathrm{pH}$ and sugar concentration (Table 5).

\begin{tabular}{|c|c|c|c|c|c|c|c|c|}
\hline Experiments & \multicolumn{3}{|c|}{ Coded Levels } & \multicolumn{3}{|c|}{ Real Values } & \multicolumn{2}{|c|}{$\left(Y_{i}\right):$ Biomass $(\mathrm{g} / \mathrm{L})$} \\
\hline 02 & +1 & -1 & -1 & 37 & 3.6 & 44.1 & 15.99 & 17.45 \\
\hline 03 & -1 & +1 & -1 & 29 & 7.3 & 44.1 & 25.70 & 27.80 \\
\hline 06 & +1 & -1 & +1 & 37 & 3.6 & 170.9 & 29.86 & 29.59 \\
\hline 07 & -1 & +1 & +1 & 29 & 7.3 & 170.9 & 20.78 & 21.16 \\
\hline 08 & +1 & +1 & +1 & 37 & 7.3 & 170.9 & 23.51 & 25.42 \\
\hline 09 & -1.68 & 0 & 0 & 27 & 5.5 & 107.5 & 22.61 & 24.06 \\
\hline 10 & +1.68 & 0 & 0 & 39 & 5.5 & 107.5 & 26.20 & 22.15 \\
\hline 11 & 0 & -1.68 & 0 & 33 & 2.4 & 107.5 & 26.00 & 28.21 \\
\hline 15 & 0 & 0 & 0 & 33 & 5.5 & 107.5 & 40.00 & 40.07 \\
\hline 16 & 0 & 0 & 0 & 33 & 5.5 & 107.5 & 40.00 & 40.07 \\
\hline 17 & 0 & 0 & 0 & 33 & 5.5 & 107.5 & 40.00 & 40.07 \\
\hline 18 & 0 & 0 & 0 & 33 & 5.5 & 107.5 & 40.00 & 40.07 \\
\hline 19 & 0 & 0 & 0 & 33 & 5.5 & 107.5 & 40.00 & 40.07 \\
\hline 20 & 0 & 0 & 0 & 33 & 5.5 & 107.5 & 40.00 & 40.07 \\
\hline
\end{tabular}

Table 5. The central composite design for biomass production.

* Each experiment was carried out twice and the average value is used here.

Using the results obtained in diverse experiments, the correlation gives the influence of temperature $\left(X_{1}\right)$, initial $\mathrm{pH}\left(X_{2}\right)$ and total sugar concentration $\left(X_{3}\right)$ on the response. This correlation is obtained by Minitab 16 software and expressed by the following second order polynomial (Equation (7)):

$$
Y_{i}=40.074-0.568 X_{1}-0.090 X_{2}+1.373 X_{3}-5.999 X_{1}^{2}-4.248 X_{2}^{2}-5.893 X_{3}^{2}-0.070 X_{1} X_{2}+2.772 X_{1} X_{3}-1.925 X_{2} X_{3}
$$

Table 6 shows the coefficient regression corresponding with $t$ and $p$-values for all the linear, quadratic and interaction effects of parameters tested. A positive sign in the $t$-value indicates a synergistic effect, while a negative sign represents an antagonistic effect of the parameters on the biomass concentration [29]. 
Table 6. Estimated regression coefficients of $\mathrm{t}$ and $p$-values of the model.

\begin{tabular}{ccccc}
\hline Terms & Coefficients & Square Error & $\boldsymbol{t}$-Value & $p$ \\
\hline$\beta_{0}$ & 40.0744 & 1.3912 & 28.806 & 0.000 \\
$\beta_{1}$ & -0.5684 & 0.9230 & -0.616 & 0.552 \\
$\beta_{2}$ & -0.0907 & 0.9230 & -0.098 & 0.924 \\
$\beta_{3}$ & 1.3739 & 0.9230 & 1.488 & 0.167 \\
$\beta_{11}$ & $-\mathbf{6 . 0 0 0 0}$ & $\mathbf{0 . 8 9 8 5}$ & $-\mathbf{6 . 6 7 7}$ & $\mathbf{0 . 0 0 0}$ \\
$\beta_{22}$ & $-\mathbf{4 . 2 4 8 1}$ & $\mathbf{0 . 8 9 8 5}$ & $\mathbf{- 4 . 7 2 8}$ & $\mathbf{0 . 0 0 1}$ \\
$\beta_{33}$ & $-\mathbf{5 . 8 9 3 9}$ & $\mathbf{0 . 8 9 8 5}$ & $-\mathbf{6 . 5 5 9}$ & $\mathbf{0 . 0 0 0}$ \\
$\beta_{12}$ & -0.0700 & 1.2060 & -0.058 & 0.955 \\
$\beta_{13}$ & $\mathbf{2 . 7 7 2 5}$ & $\mathbf{1 . 2 0 6 0}$ & $\mathbf{2 . 2 9 9}$ & $\mathbf{0 . 0 4 4}$ \\
$\beta_{23}$ & -1.9250 & 1.2060 & -1.596 & 0.142 \\
\hline \multicolumn{5}{c}{}
\end{tabular}

The examination of Table 6 shows that all coefficient regression of the quadratic terms are statistically significant $p \leq 0.05$ and negatively affect the biomass production (Figure 2). In contrast all coefficient regression of linear and interaction terms were statistically not significant $p>0.005$, except the interaction term $X_{1} X_{3}$, which is significant $p=0.044$ and has a synergistic effect on the response (Figure 2).

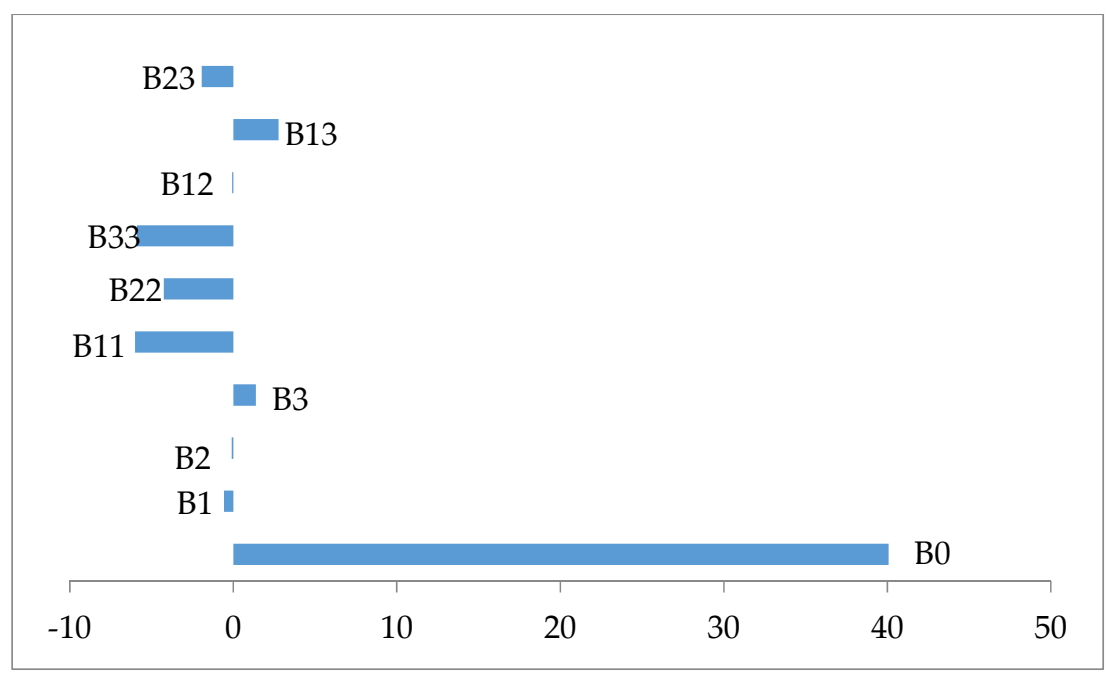

Figure 2. Variable effect signification on a biomass production.

The analysis of variance (ANOVA) of the coefficient regression for the cell growth production (Table 7) demonstrates that the model is significant due to the $F$-value of 11.43 and the low probability $p$ value $(p=0.000)$. Generally, the $F$-value with a low probability $p$-value indicates a high significance of the regression model [30].

Moreover, the coefficient of determination $\left(R^{2}\right)$ measures the fit between the model and experimental data. Figure 3 was also determined to evaluate the regression model. In this study, the obtained value of $R^{2}$ is 0.911 approximate to 1 , which justifies an excellent consistency of the model [31]. On the other hand, the obtained $R^{2}$ implies that $91.1 \%$ of the sample variation in the cell growth is attributed to the independent variables. This value indicates also that only $8.86 \%$ of the variation is not explained by the model. 
Table 7. Analysis of variance (ANOVA).

\begin{tabular}{ccccccc}
\hline Source & DF & Seq SS & Adj SS & Adj MS & $\boldsymbol{F}$ & $p$ \\
\hline Regression & 9 & 1196.65 & 1196.65 & 132.961 & $\mathbf{1 1 . 4 3}$ & $\mathbf{0 . 0 0 0}$ \\
Linear & 3 & 30.30 & 30.30 & 10.101 & 0.87 & 0.489 \\
A & 1 & 4.41 & 4.41 & 4.412 & 0.38 & 0.552 \\
B & 1 & 0.11 & 0.11 & 0.112 & 0.01 & 0.924 \\
C & 1 & 25.78 & 25.78 & 25.779 & 2.22 & 0.167 \\
Square & 3 & 1075.17 & 1075.17 & 358.390 & 30.80 & 0.000 \\
A $^{*}$ & 1 & 379.27 & 518.80 & 518.799 & 44.59 & 0.000 \\
$\mathrm{~B}^{*} \mathrm{~B}$ & 1 & 195.28 & 260.07 & 260.071 & 22.35 & 0.001 \\
$\mathrm{C}^{*} \mathrm{C}$ & 1 & 500.62 & 500.62 & 500.618 & 43.03 & 0.000 \\
Interaction & 3 & 91.18 & 91.18 & 30.393 & 2.61 & 0.109 \\
$\mathrm{~A}^{*} \mathrm{~B}$ & 1 & 0.04 & 0.04 & 0.039 & 0.00 & 0.955 \\
$\mathrm{~A}^{*} \mathrm{C}$ & 1 & 61.49 & 61.49 & 61.494 & 5.29 & 0.044 \\
$\mathrm{~B}^{*} \mathrm{C}$ & 1 & 29.64 & 29.64 & 29.645 & 2.55 & 0.142 \\
Residual & 10 & 116.35 & 116.35 & 11.635 & & \\
Error & & & & & & \\
\hline
\end{tabular}

DF: degrees of freedom; Seq SS: sequential sum of squares; Adj SS: adjusted, sum of squares; AdjMS: adjusted, mean of squares F: Fischer's variance ratio; P: probability value.

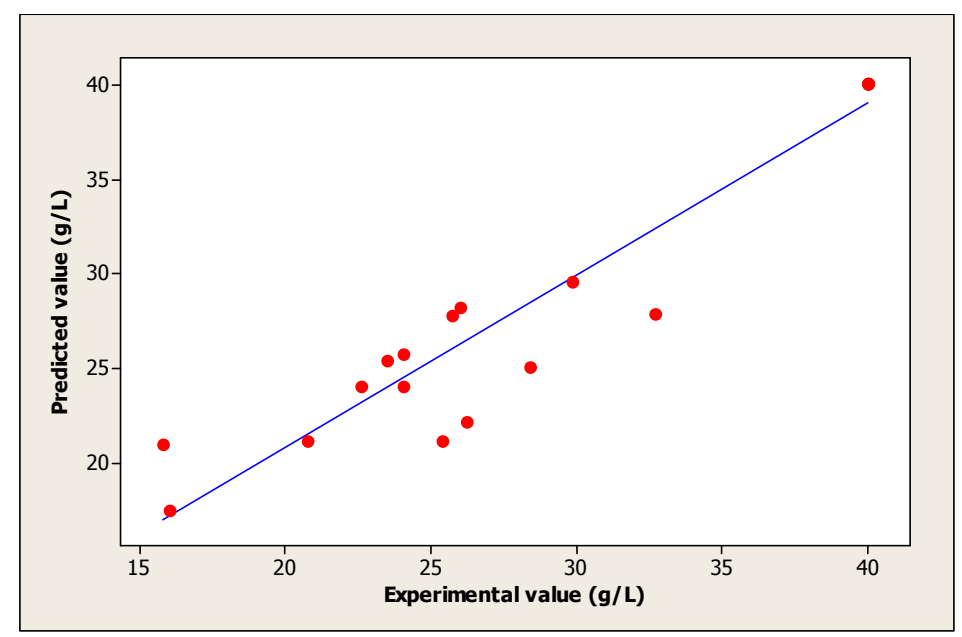

Figure 3. The fit between the model and experimental data of cell growth.

According to the literature, the study proposed by Boudjemaet al. [22] was carried out using a design of experiment to describe the batch fermentation of bioethanol and biomass production on sweet cheese whey by Saccharomyces cerevisiae DIV13-Z087C0VS. The results showed a good agreement with experimental data (a low probability $p$ value $\leq 0.000$ and a good correlation coefficient $\left(R^{2}=0.914 \%\right.$ ), which confirms a high significance of the regression model. In addition, the study carried out by Bennamoun et al. [32] showed that the optimization of the medium components, which enhance the polygalacturonase activity of the strain Aureobasidium pullulans, was achieved with the aid of the same method used in the present study (response surface methodology). The obtained results showed a significance of the method used in comparison with the experimental data; a very low $p$ value $(0.001)$ and a high coefficient of determination $\left(R^{2}=0.9421\right)$.

The optimization of the response $Y_{i}$ (Biomass production) and the prediction of the optimum levels of temperature, initial $\mathrm{pH}$ and sugars concentration of fermentation were obtained. This optimization resulted in surface plots (Figure 4) and an isoresponse contour plot (Figure 5). 


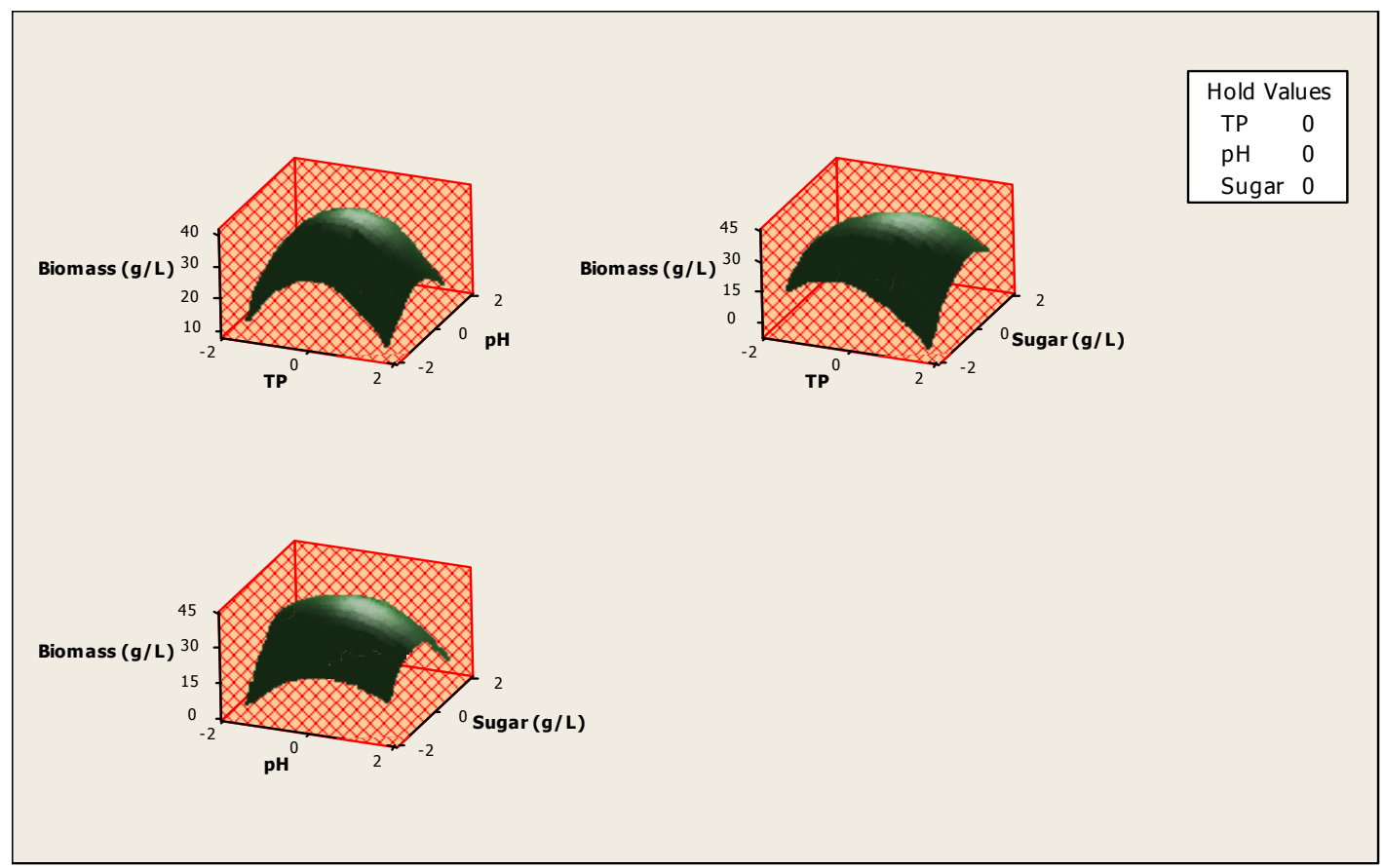

Figure 4. Surface plot for the effect of different parameters on biomass production.

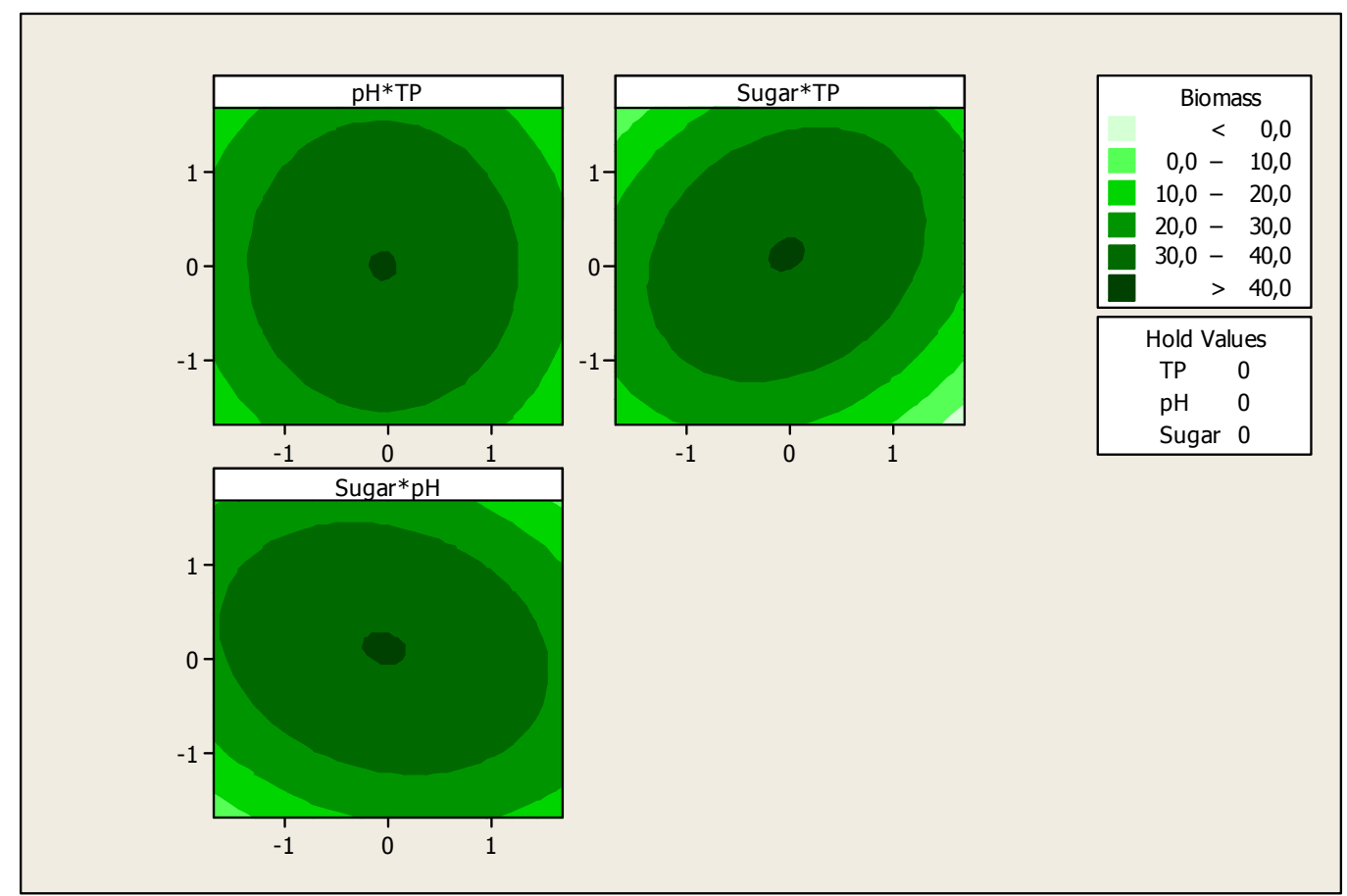

Figure 5. Isoresponse contour plot for the effect of the studied variables on biomass production.

These figures show that there is an optimum, located at the center of the field of study. In addition, the use of the minitab optimizer will give exact values of the optimum operating conditions of the process (Figure 6). 


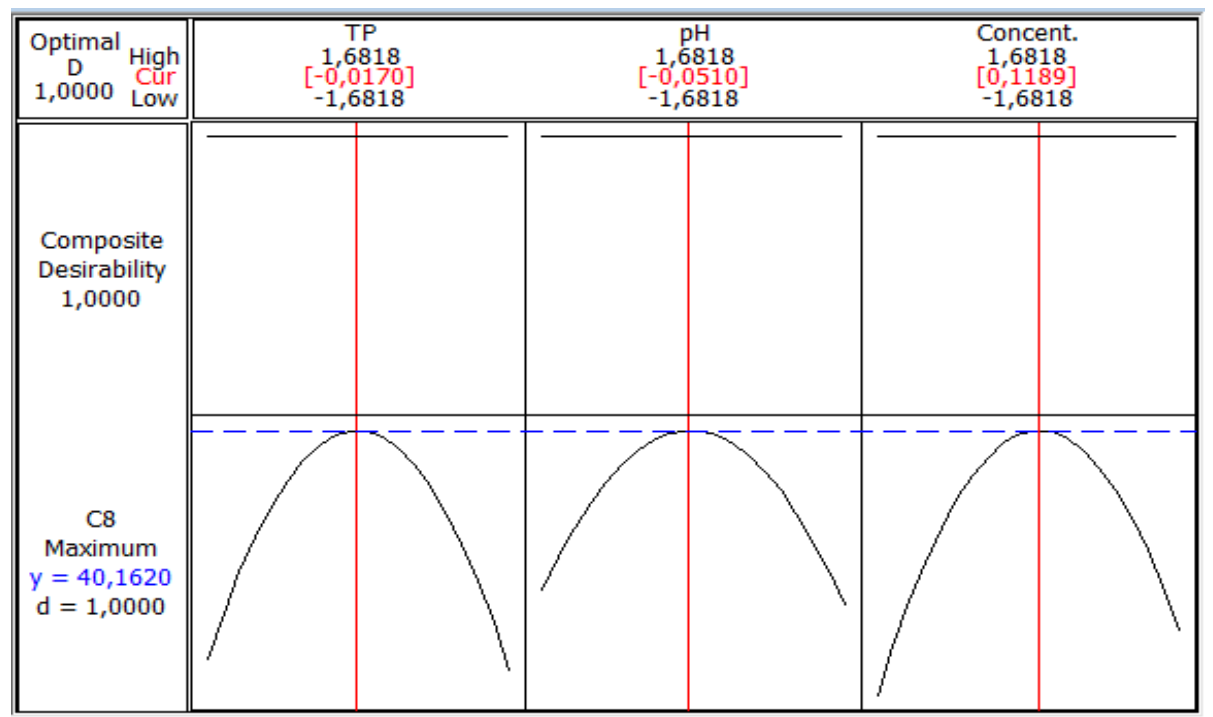

Figure 6. Coded values of optimal conditions on biomass production.

Figure 6 shows the maximum biomass production by S. cerevisiae $(40.162 \mathrm{~g} / \mathrm{L})$ corresponding to coded values of temperature $(-0.0170), \mathrm{pH}(-0.0510)$ and sugar concentration $(0.1189)$. These values are equivalent to real values of $32.9^{\circ} \mathrm{C}, 5.35$ and $70.93 \mathrm{~g} / \mathrm{L}$, respectively. Jiménez Islas et al. [27] obtained the highest cell concentration of S. cerevisiae ATCC $9763(7.9 \mathrm{~g} / \mathrm{L})$ after $26 \mathrm{~h}$ when the strain grew at $30^{\circ} \mathrm{C}$ and $\mathrm{pH} 5.5$.

The validation of the baker's yeast biomass concentration and total reducing sugar consumption, over time, at optimized conditions, are presented in Figure 7. In the beginning, the biomass concentration increased with a decrease in the sugar level, reaching the maximum $(40 \mathrm{~g} / \mathrm{L})$ at $16 \mathrm{~h}$ of fermentation, which confirms the biomass obtained by the CCD predictions (40.1620) (Figure 6). After this period, the diminution of a biomass concentration was observed, which could be explained by the sugar consumption, which ran out after18 $\mathrm{h}$ of fermentation.

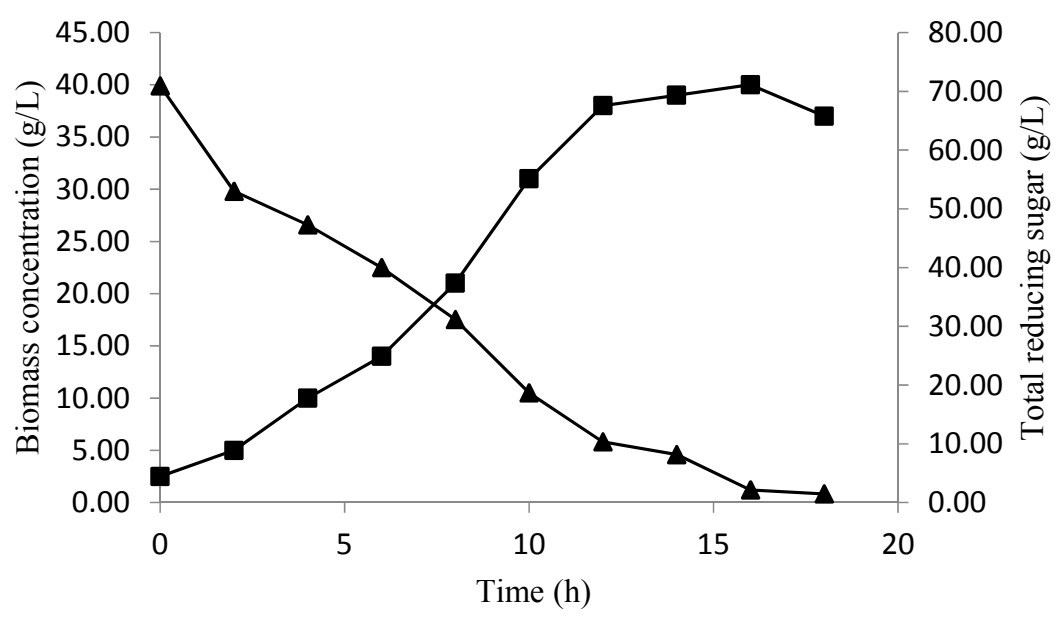

Figure 7. The biomass production ( $\mathbf{\square})$, and total reducing sugar consumption $(\boldsymbol{\Lambda})$ over time at optimized conditions.

The same results were obtained by Nancib et al. [33], where the production of biomass from baker's yeast $S$. cerevisiae on a medium containing date byproducts was $40 \mathrm{~g} / \mathrm{L}$. Khan et al. [34] used six different strains of $S$. cerevisiae in fermentation medium containing date extract (with 60\% sugars), 
in addition to $2 \mathrm{~g} / \mathrm{L}$ ammonium sulfate and $50 \mathrm{mg} / \mathrm{L}$ biotin. Their results showed that the theoretical yields were about $42.8 \%$. In addition, Al Obaidi et al. [35] studied two substrates i.e, date syrup and molasses for the propagation of baker's yeast strain S. cerevisiae on a pilot plant scale. The results showed that higher productivity of baker's yeast was observed when date extract was used. Other results were obtained in several studies using an alternative substrate of fermentation. In fact, the optimal biomass production $(6.3 \mathrm{~g} / \mathrm{L})$ was depicted at $24 \mathrm{~h}$ using Saccharomyces cerevisiae DIV13-Z087C0VS on a medium containing sweet cheese as a sole carbon source [22]. On the other hand, the production of baker's yeast from apple pomace gives a yield of $0.48 \mathrm{~g} / \mathrm{g}$ [36]. Therefore, it was concluded from these studies that the medium containing the date extract as a sole carbon source is an excellent fermentation medium for baker's yeast production.

The results of the kinetic parameters of $S$. cerevisiae growth with the different kinetic models based on the curve fitting method are presented in Table 8.

Table 8. Kinetic parameters of S. cerevisiae growth and substrate utilization using unstructured models.

\begin{tabular}{lcccc}
\hline Kinetic Models & \multicolumn{3}{c}{ Parameters Estimation } \\
\hline$R^{2}$ & $K s(\mathrm{~g} / \mathrm{L})$ & $\mu_{\max }\left(\mathrm{h}^{-1}\right)$ & $X_{m}$ \\
\hline Monod & 0.945 & 0.228 & 0.496 & - \\
Verhulst & 0.981 & - & 0.376 & 15.04 \\
Tessier & 0.979 & -9.434 & 0.408 & \\
\hline
\end{tabular}

The curve fitting of cell growth using the Monod model $(1 / \mu$ versus $1 / \mathrm{S})$ is presented in Figure 8. Based on the results obtained in Table 8 for this model the $\mu_{\max }$ and $K s$ were evaluated as $0.496 \mathrm{~h}^{-1}$ and $0.228 \mathrm{~g} / \mathrm{L}$, respectively. These values indicate a rapid cell growth due to the high value of the specific growth rate and an elevated affinity between substrate consumption and cell growth thanks to the small half-saturation constant. In this case, $R^{2}$ was also fitted on 0.945 . According to the results obtained, the Monod kinetic model is an appropriate model to make the kinetic performance of this strain.

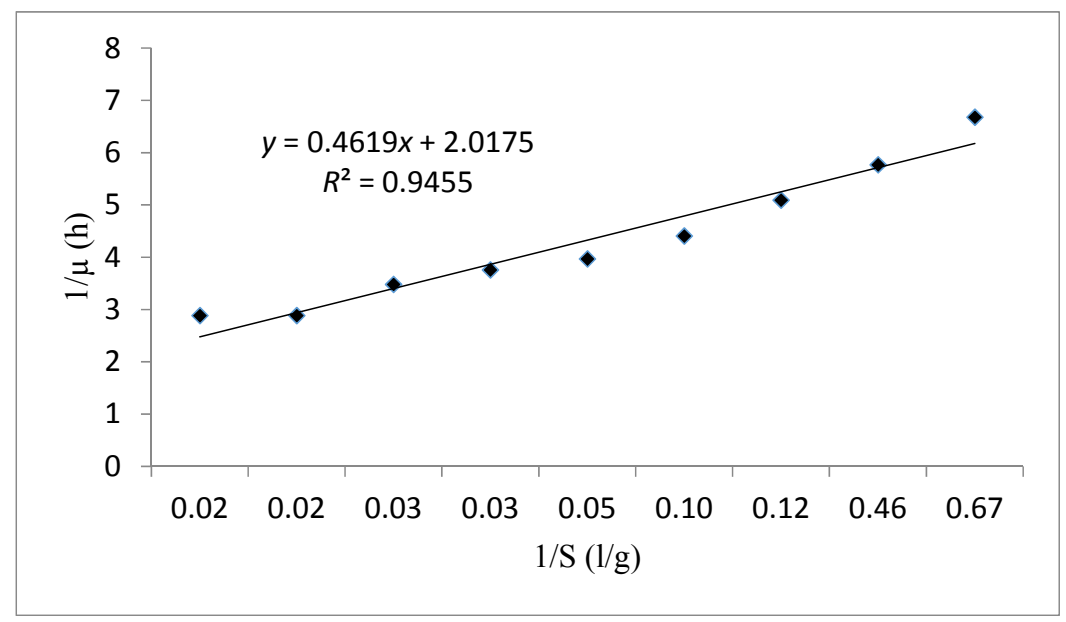

Figure 8. The Lineweaver Burk linear plot fitting the experimental data using the Monod kinetic model.

Figure 9 illustrates the linear curve fitting ( $\mu$ versus $X$ ) to examine the reliability of cell kinetic performance via the Verhulst model. The analysis of the results obtained showed that the experimental data of the cell growth and substrate consumption in batch system have an excellent fitness with this model $\left(R^{2}=0.981\right)$. The maximum specific growth rate $\left(\mu_{\max }\right)$ and the maximum concentration of biomass $\left(X_{m}\right)$, were $0.376 \mathrm{~h}^{-1}$ and $15.04 \mathrm{~g} / \mathrm{L}$ respectively (Table 8). Higher values of these parameters indicated a rapid growth of the biomass which confirms the goodness of fit of the Verhulst model. 


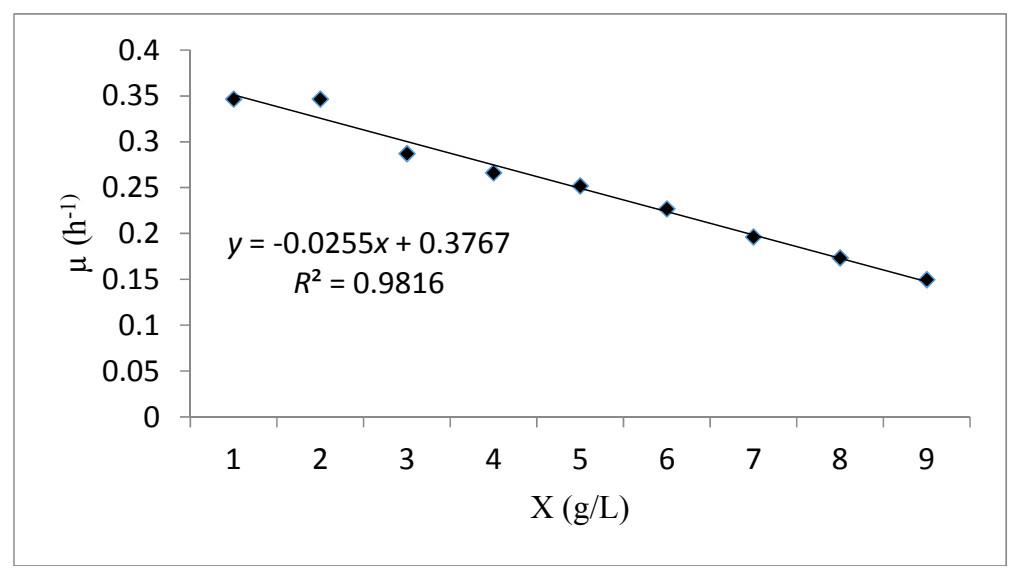

Figure 9. A plot fitting the experimental data using the Verhulst kinetic model.

The kinetic behavior fitness of $S$. cerevisiae with the Tessier kinetic model is illustrated in Figure 10. The coefficient of correlation $R^{2}$ equal to 0.979 and the estimation parameters ( $\mu_{\max }$ and Ks) shown in Table 8 were 0.408 and -9.434 respectively. The examination of the cell growth fitting curve with the Tessier kinetic model showed that, even though they were appropriate $R^{2}$ and $\mu_{\max }$ values, the model is not suitable with the experimental data due to the illogical value of the half-saturation constant (negative Ks).

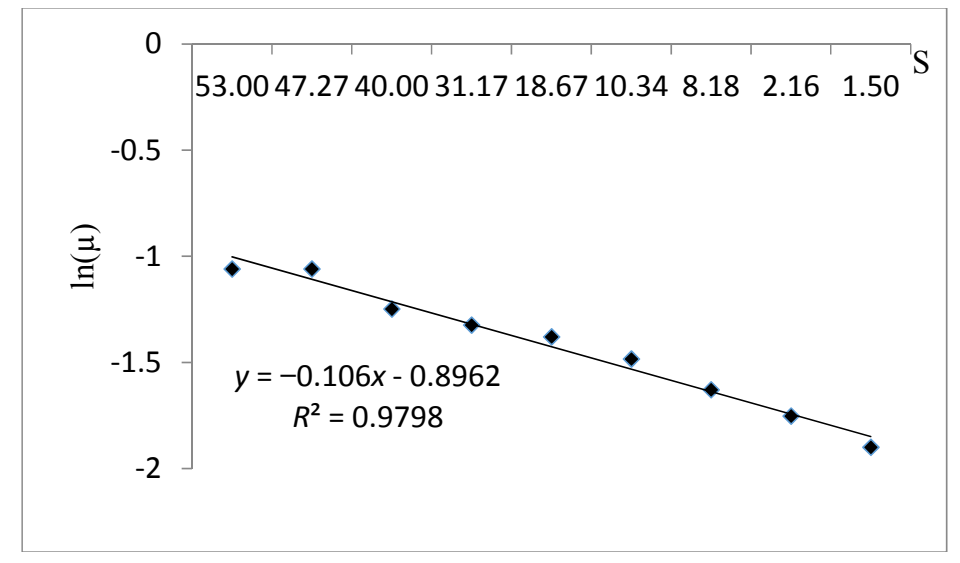

Figure 10. A plot fitting the experimental data using the Tessier kinetic model.

The comparison between the three kinetic models tested in this study showed that the Verhulst kinetic model with $R^{2}=0.981$ was the best and most appropriate model to explain $S$. cerevisiae growth and substrate utilization. Approximate results were obtained by Ardestani and Shafiei [37], who proved that the Verhulst kinetic model with $R^{2}$ equal to 0.97 was the most appropriate to describe the biomass growth rate of $S$. cerevisiae. In contrast, Ardestani and Kasebkar [38], applied an unstructured kinetic model of Aspergillus niger growth and substrate uptake in a submerged batch culture and have confirmed that Monod and Verhulst kinetic models were not in an acceptable range to fit a growth of Aspergillus niger.

A profile of biomass and total reducing sugar concentration during fermentation time is compared to the values predicted by the equations model obtained in Figure 11. 


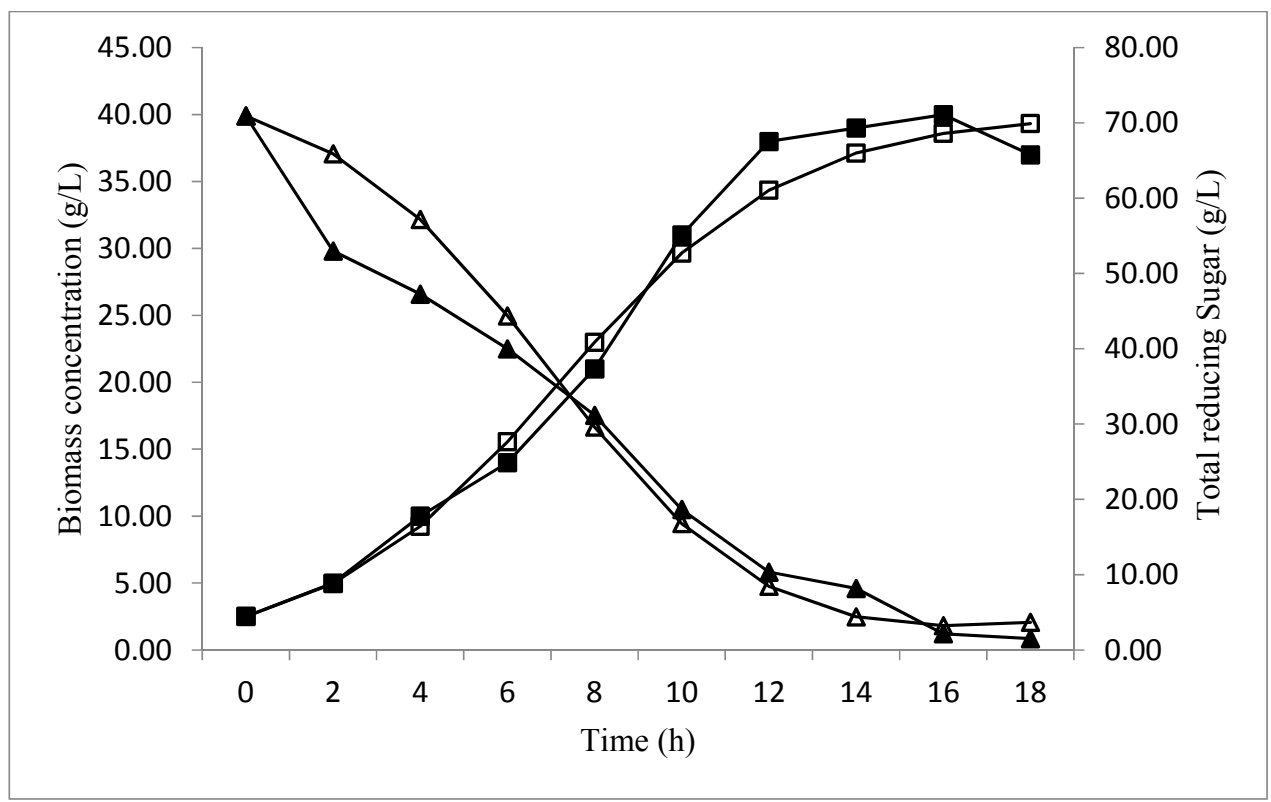

Figure 11. The comparison between predicted $(\square)$, experimental data ( $\mathbf{\square})$ for biomass production of baker's yeast; and predicted $(\Delta)$, experimental data $(\boldsymbol{\Delta})$, for total reducing sugar consumption.

At the beginning of the fermentation, values of biomass between predicted and experimental data were approximately the same. However, after $10 \mathrm{~h}$ and until the end of the fermentation, the difference was remarkable. In fact, the values relative to biomass were inferior compared to the values predicted by the Verhulst model. The correlation coefficient is 0.992 . As for total reducing sugar concentration, the values obtained by the Leudeking Piret model were lower than those predicted in the first $7 \mathrm{~h}$ only. After this period, total reducing sugar values were almost identical. The correlation coefficient is 0.984 . In addition, the parameter values of $p$ and $q$ were optimized using the experimental data for substrate based on the square minimized between observed and predicted data. Excel software illustrated the values of $p=2.1235$ and $q=-0.0256 \mathrm{~h}^{-1}$. On the basis of these results, good correlation coefficients showed that the proposed Verhulst model and the Luedeking Piret model were adequate to explain the development of biomass production process on date extract. According to the literature, the study proposed by Kara Ali et al. [39] was carried out using the logistic empirical kinetic model and Leudeking Piret model to describe batch fermentation of P. caribbica on inulin. The results showed a good agreement with the experimental data $\left(R^{2}=0.91\right)$ for cell growth and $\left(R^{2}=0.95\right)$ for substrate consumption. In addition, the values of $\mathrm{p}$ and $\mathrm{q}$ were 14.735 and $-0.0771 / \mathrm{h}$, respectively, thus, the model equations were found to represent an appropriate kinetic model for successfully describing yeast cell growth in batch fermentation. Another kinetic study proposed by Zajšek and Goršek [40] which used the unstructured models of batch kefir fermentation kinetics for ethanol production by mixed natural microflora confirmed that the growth of kefir grains could be expressed by a logistic function model, and it can be employed for the development and optimization of bio-based ethanol production processes. Furthermore, the study of Pazouki et al. [41] which illustrated the kinetic models of cell growth, substrate utilization and bio-decolorization of distillery waste water by Aspergillus fumigatus UB260. This study confirmed that the Logistic equation for the growth and the Leudeking Piret kinetic model for substrate utilization were able to fit the experimental data $\left(R^{2}=0.984\right)$. The coefficient equation were also calculated $(p$ and $q)$ their values were $1.41(\mathrm{~g} / \mathrm{g})$ and $0.0007(1 / \mathrm{h})$ respectively.

\section{Conclusions}

Microbial fermentation is complex and it is quite difficult to understand its complete details process. The central composite design (CCD) proposed in this study seems pertinent to describe the 
optimum biomass production of S. cerevisiae. A second order polynomial model was developed to evaluate the quantitative effects of temperature, $\mathrm{pH}$ and reducing sugar concentration in order to discover the optimum conditions for the biomass production from date extract. According to the experimental results, a maximum biomass concentration of $40 \mathrm{~g} / \mathrm{L}$ was obtained at the optimum condition of temperature $\left(32.9^{\circ} \mathrm{C}\right), \mathrm{pH}(5.35)$ and total reducing sugars $(70.93 \mathrm{~g} / \mathrm{L})$.

In addition, among three unstructured kinetic models, both Monod and Verhulst models represent the experimental data of biomass production kinetics; nevertheless, the Verhulst model was the most suitable model to signify the baker's yeast production on date extract medium.

Acknowledgments: This work was financially supported by University Frères Mentouri Constantine 1. The authors are very grateful to the students; MALKI R. and LEKIKOT Z. (UMC-1, Algeria) for the collaboration and assistance to carry out this study.

Author Contributions: M.K. performed the experiments, wrote the paper; N.O. and A.B. helped in the statistical analysis and modeling; A.A.K and S.B. helped in interpretation and analysis of data, C.R. revised English; N.K.C. supervised the activities, contributed laboratory, reagents and materials.

Conflicts of Interest: The authors declare no conflict of interest.

\section{References}

1. Pandey, A.; Soccol, C.R.; Selvakumar, P.; Soccol, V.T.; Krieger, N.; Fontana, J.D. Recent developments in microbial inulinases, its production, properties and industrial applications. Appl. Biochem. Biotechnol. 1999, 81, 35-52. [CrossRef]

2. Richelle, A.; Ben Tahar, I.; Hassouna, M.; Bogaerts, P.H. Macroscopic modelling of bioethanol production from potato peel wastes in batch cultures supplemented with inorganic nitrogen. Bioprocess Biosyst. Eng. 2015, 38, 1819-1833. [CrossRef] [PubMed]

3. Tang, L.; Wang, W.; Zhou, W.; Cheng, K.; Yang, Y.; Liu, M.; Cheng, K.; Wang, W. Three-pathway combination for glutathione biosynthesis in Saccharomyces cerevisiae. Microb. Cell Fact. 2015, 14, 139. [CrossRef] [PubMed]

4. Lin, Y.; Tanaka, S. Ethanol fermentation from biomass resources: current state and prospects. Appl. Microbiol. Biotechnol. 2006, 69, 627-642. [CrossRef] [PubMed]

5. Martin, C.; Galbe, M.; Wahlbom, C.F.; Hahn-Hagerdal, B.; Jonsson, L.F. Ethanol production from enzymatic hydrolysates of sugarcane bagasse using recombinant xylose utilizing Saccharomyces cerevisiae. Enzyme Microb. Technol. 2012, 31, 274-282. [CrossRef]

6. Neagu, C.B.; Bahrim, G. Comparative study of different methods of hydrolysis and fermentation for bioethanol obtaining from inulin and inulin rich feedstock. Food Ind. 2012, 13, 63-68.

7. Mussato, S.I.; Machado, E.M.S.; Carneiro, L.M.; Teixeira, J.A. Sugar metabolism and ethanol production by different yeast strains from coffee industry wastes hydrolysates. Appl. Energy 2012, 92, 763-768. [CrossRef]

8. Chibane, H.; Benamara, S.; Noui, Y.; Djouab, A. Some Physichemical and Morphological Characterizations of Three Varietes of Algerian Common Dates. Eur. J. Sci. Res. 2007, 18, 134-140.

9. Kacem-Chaouche, N.; Dehimat, L.; Meraihi, Z.; Destain, J.; Kahlat, K.; Thonart, P.H. Decommissioned dates: chemical composition and fermentation substrate for the production of extracellular catalase by an Aspergillus phoenicis mutant. Agric. Biol. J. N. Am. 2013, 4, 41-47. [CrossRef]

10. Peyron, G. Cultiver le Palmier Dattier; Technical Centre for Agricultural and Rural Cooperation (CTA): Wageningen, The Netherlands, 2000; p. 110.

11. Alexeeva, Y.V.; Ivanova, E.P.; Bakunina, I.Y.; Zvaygintseva, T.N.; Mikhailov, V.V. Optimization of glycosidases production by Pseudoalteromonasissachenkonii. KMM 3549T. Lett. Appl. Microbiol. 2002, 35, 343-346. [CrossRef] [PubMed]

12. Patidar, P.; Agrawal, D.; Banerjee, T.; Patil, S. Chitinase production by Beauveriafelina. RD 101: Optimization of parameters under solid substrate fermentation conditions. World J. Microbiol. Biotechnol. 2005, 21, $93-95$. [CrossRef]

13. Rajendhran, J.; Krishnakumar, V.; Gunasekaran, P. Optimization of a fermentation medium for the production of Penicillin G acylase from Bacillus sp. Lett. Appl. Microbiol. 2002, 35, 523-527. [CrossRef] [PubMed]

14. Schmidt, F.R. Optimization and scale up of industrial fermentation processes. Appl. Microbiol. Biotechnol. 2005, 68, 425-435. [CrossRef] [PubMed] 
15. Singh, B.; Satyanarayana, T.A. Marked enhancement in phytase production by a thermophilic mould Sporotrichum thermophile using statistical designs in a cost-effective cane molasses medium. J. Appl. Microbiol. 2006, 101, 344-352. [CrossRef] [PubMed]

16. Sayyad, S.A.; Panda, B.P.; Javed, S.; Ali, M. Optimization of nutrient parameters for lovastatin production by Monascus purpureus MTCC 369 under submerged fermentation using response surface methodology. Appl. Microbiol. Biotechnol. 2007, 73, 1054-1058. [CrossRef] [PubMed]

17. Kennedy, M.; Krouse, D. Strategies for improving fermentation medium performance: A review. J. Ind. Microbiol. Biotechnol. 1999, 23, 456-475. [CrossRef]

18. Chakravarti, R.; Sahai, V. Optimization of compaction production in chemically defined production medium by Penicilium citrinum using statistical methods. Process Biochem. 2002, 38, 481-486. [CrossRef]

19. Kar, B.; Banerjee, R.; Bhattachaaryya, B.C. Optimization of physicochemical parameters for gallic acid production by evolutionary operation-factorial design techniques. Process Biochem. 2002, 37, 1395-1401. [CrossRef]

20. Naveena, B.J.; Altaf, M.; Bhadriah, K.; Reddy, G. Selection of medium components by Plackett-Burman design for production of $\mathrm{L}(+)$ lactic acid by Lactobacillus amylophilus GV6 in SSF using wheat bran. Bioresour. Technol. 2005, 96, 485-490. [CrossRef] [PubMed]

21. Shafaghat, H.; Najafpour, G.D.; Rezaei, P.S.; Sharifzadeh, M. Optimal growth of saccharomyces cerevisiae (ptcc 24860) on pretreated molasses for the ethanol production: The application of the response surface methodology. Chem. Ind. Chem. Eng. Q. 2010, 16, 199-206. [CrossRef]

22. Boudjema, K.; Fazouane-naimi, F.; HellaL, A. Optimization of the Bioethanol Production on Sweet Cheese Whey by Saccharomyces cerevisiae DIV13-Z087C0VS using Response Surface Methodology (RSM). Rom. Biotech. Lett. 2015, 20, 10814-10825.

23. Montgomery, D.C. Design and Analysis of Experiments, 5th ed.; John Wiley \& Sons, Inc.: New York, NY, USA, 2009.

24. Bouhadi, D.; Raho, B.; Hariri, A.; Benattouche, Z.; Sahnouni, F.; OuldYerou, K.; Bouallam, S.A. Utilization of Date Juice for the Production of Lactic Acid by Streptococcus Thermophilus. J. Appl. Biotechnol. Bioeng. 2017, 3, 00071 .

25. Kocher, G.S.; Uppal, S. Fermentation variables for the fermentation of glucose and xylose using Saccharomyces cerevisiae Y-2034 and Pachysolan tannophilus Y-2460. Indian J. Biotechnol. 2013, 12, 531-536.

26. Dubois, M.; Gilles, K.A.; Hamilton, J.K.; Rebers, P.A.; Smith, F. Colorimetric Method for Determination of Sugars and Related Substances. Anal. Chem. 1956, 28, 350-356. [CrossRef]

27. Jiménez-Islas, D.; Páez-Lerma, J.; Soto-Cruz, N.O.; Gracida, J. Modelling of Ethanol Production from Red Beet Juice by Saccharomyces cerevisiae under Thermal and Acid Stress Conditions. Food Technol. Biotechnol. 2014, 52, 93-100.

28. Juska, A. Minimal models of growth and decline of microbial populations. J. Theor. Biol. 2011, 269, 195-200. [CrossRef] [PubMed]

29. Le Man, H.; Behera, S.K.; Park, H.S. Optimization of operational parameters for ethanol production from Korean food waste leachate. Int. J. Environ. Sci. Tech. 2010, 7, 157-164. [CrossRef]

30. Rene, E.R.; Jo, M.S.; Kim, S.H.; Park, H.S. Statistical analysis of main and interaction effects during the removal of BTEX mixtures in batch conditions using wastewater treatment plant sludge microbes. Int. J. Environ. Sci. Technol. 2007, 4, 177-182. [CrossRef]

31. Annuar, M.S.M.; Tan, I.K.P.; Ibrahim, S.; Ramachandran, K.B. A Kinetic Model for Growth and Biosynthesis of Medium-Chain-Length Poly-(3-Hydroxyalkanoates) in Pseudomonas putida. Braz. J. Chem. Eng. 2008, 25, 217-228. [CrossRef]

32. Bennamoun, L.; Hiligsmann, S.; Dakhmouche, S.; Ait-Kaki, A.; Labbani, F.Z.K.; Nouadri, T.; Meraihi, Z.; Turchetti, B.; Buzziniand, P.; Thonart, P. Production and Properties of a Thermostable, pH-Stable Exo-Polygalacturonase Using Aureobasidium pullulans Isolated from Saharan Soil of Algeria Grown on Tomato Pomace. Foods 2016, 5, 72. [CrossRef] [PubMed]

33. Nancib, N.; Nancib, A.; Boudrant, J. Use of waste date products in the formation of baker's yeast biomass by Saccharomyces cerevisiae. Bioresour. Technol. 1997, 60, 67-71. [CrossRef]

34. Khan, J.A.; Abulnaja, K.O.; Kumosani, T.A.; Abou-Zaid, A.A. Utilization of Saudi date sugars in production of baker's yeast. Bioresour. Technol. 1995, 53, 63-66. [CrossRef] 
35. Al Obaidi, Z.S.; Mohamed, N.A.; Hasson, N.A.; Jassem, M.A. Semi-Industrial production of Baker's yeast using date extract and molasses. J. Agric. Water Resour. Res. 1986, 5, 162-174.

36. Bhushan, S.; Joshi, V.K. Baker's yeast production under fed-batch culture from apple pomace. J. Sci. Ind. Res. 2006, 65, 72-76.

37. Ardestani, F.; Shafiei, S. Non-Structured Kinetic Model for the Cell Growth of Saccharomyces cerevisiae in a Batch Culture. Iranica J. Energy Environ. 2014, 5, 8-12. [CrossRef]

38. Ardestani, F.; Kasebkar, R. Non-Structured Kinetic Model of Aspergillus niger Growth and Substrate Uptake in a Batch Submerged Culture. Br. Biotechnol. J. 2014, 4, 970-979. [CrossRef]

39. Kara Ali, M.; Hiligsmann, S.; Outili, N.; Cherfia, R.; KacemChaouche, N. Kinetic models and parameters estimation study of biomass and ethanol production from inulin by Pichiacaribbica (KC977491). Afr. J. Biotechnol. 2017, 16, 124-131. [CrossRef]

40. Zajšek, K.; Goršek, A. Modelling of batch kefir fermentation kinetics for ethanol production by mixed natural microflora. Food Bioprod. Process. 2010, 88, 55-60. [CrossRef]

41. Pazouki, M.; Najafpour, G.; Hosseini, M.R. Kinetic models of cell growth, substrate utilization and bio-decolorization of distillery wastewater by Aspergillus fumigatus UB260. Afr. J. Biotechnol. 2008, 7, 1369-1376. [CrossRef]

(C) 2017 by the authors. Licensee MDPI, Basel, Switzerland. This article is an open access article distributed under the terms and conditions of the Creative Commons Attribution (CC BY) license (http://creativecommons.org/licenses/by/4.0/). 